\title{
PERENCANAAN STRATEGIS DENGAN PENDEKATAN BALANCE SCORECARD PADA PERUSAHAAN PROPERTI (STUDI KASUS: ELANG GROUP)
}

\author{
Ratih Wulandari ${ }^{*}$, Idqan Fahmi*), dan Rita Nurmalina ${ }^{* *}$ \\ ${ }^{*}$ Sekolah Bisnis, Institut Pertanian Bogor \\ Jl. Raya Pajajaran, Bogor 16151 \\ **) Departemen Agribisnis, Fakultas Ekonomi dan Manajemen, Institut Pertanian Bogor \\ Jl. Kamper Wing 4 Level 5 Kampus IPB, Bogor, Jawa Barat 16680
}

\begin{abstract}
The objectives of this study were to determine the strategic factors of the internal and external environments, analyze alternative strategies, to develop strategic targets and strategic maps, set key performance indicator (KPI), and determine the weight of each balanced scorecard perspective (BSC), and weight of each KPI. The research methods used were SWOT and BSC analysis. The business environment identification conducted at Elang Group resulted in eight internal factors and five external factors that influence the company's strategy to survive and to become more competitive. Following this, the process of SWOT analysis was carried out. There are four alternative strategies that can be implemented by Elang Group in improving its performance. The result of SWOT analysis was then translated into 15 strategic targets that form a causal relationship. The design of key performance indicators (KPI) determined 25 KPI divided into four Balanced Scorecard perspectives. In the financial perspective, the highest average KPI weight for return on investment (ROI) is 41,4 percent.
\end{abstract}

Keywords: balance scorecard, SWOT, key performance indicators, property, Elang group

\begin{abstract}
ABSTRAK
Tujuan dari penelitian ini adalah menetapkan faktor-faktor strategis dari lingkungan internal dan eksternal; menganalisis alternatif strategi; menyusun sasaran strategis dan peta strategis; menetapkan key performance indicator (KPI); dan menetapkan bobot dari masing-masing perspektif balanced Scorecard (BSC), dan bobot dari masing-masing KPI. Metode penelitian yang digunakan adalah analisis SWOT dan BSC. Hasil identifikasi lingkungan bisnis yang dilakukan di Elang Group terdapat delapan faktor internal di perusahaan, dan lima faktor external perusahaan yang berpengaruh terhadap strategi perusahaan untuk dapat bertahan dan semakin kompetitif. Dari hasil identifikasi kemudian dilakukan proses analisis SWOT. Terdapat empat alternatif strategi yang dapat dilakukan oleh Elang Group dalam meningkatkan kinerjanya. Hasil dari analisis SWOT, kemudian dijabarkan kedalam sasaran-sasaran strategis yang membentuk hubungan sebab akibat. Terdapat 15 sasaran strategis (SS). Perancangan key performance indicators (KPI) ditetapkan KPI sebanyak 25 KPI yang terbagi dalam empat perspektif Balanced Scorecard. Pada perspektif finansial didapatkan bobot rata-rata KPI tertinggi untuk return on investment (ROI) sebesar 41,4 persen.
\end{abstract}

Kata kunci: Balance Scorecard, SWOT, key performance indicators, property, Elang group

\footnotetext{
${ }^{1}$ Alamat Korespondensi:

Email: ratih.moeslemah@gmail.com
} 


\section{PENDAHULUAN}

Indonesia merupakan salah satu negara dengan perekonomian terbesar di Asia Pasifik. Dengan kondisi politik yang stabil, Indonesia terus tumbuh dan membuka peluang-peluang investasi. Pertumbuhan ekonomi Indonesia tetap kuat walaupun terjadi perlambatan dalam beberapa tahun terakhir. Menurut data dari Badan Pusat Statistik (BPS) pada tahun 2016 menyebutkan bahwa ekonomi Indonesia tumbuh 5,04\% pada kuartal keempat 2015 , naik dari $4,7 \%$ pada kuartal sebelumnya. Pertumbuhan ekonomi ini menurut BPS didorong oleh peningkatan belanja pemerintah sebesar $7,3 \%$ secara tahunan dan kenaikan investasi sebesar $6,9 \%$. Semakin membaiknya perekonomian Indonesia menyebabkan peningkatan daya beli yang semakin membaik. Dengan populasi terbesar keempat di dunia, Indonesia menawarkan jumlah kelas menengah yang terus tumbuh serta daya beli konsumen yang tinggi. Penyediaan dan kebutuhan tempat tinggal secara alamiah akan terus meningkat seiring dengan bertambahnya jumlah penduduk. Dengan pertimbangan tersebut dari sisi permintaan akan properti dan real estate maka diprediksikan bahwa bisnis properti dari tahun 2010 keatas akan terus menunjukkan peningkatan. Dari sisi penawaran, bisnis properti dan real estate akan mengikuti demand, terutama sektor perumahan, perhotelan, kondominium dan perkantoran, rumah toko (Ruko) dan rumah kantor (Rukan).

Indeks Harga Properti Residensial Indonesia (IHPR) adalah suatu indeks yang mencerminkan harga properti secara umum pada pasar primer (developer) di seluruh Indonesia atau semacam pengukuran IHSG untuk properti. Seperti pada Gambar 1 menunjukkan perkembangan indeks harga properti residensial dari kuartal ke kuartal (tiga bulanan). BI mencatat per triwulan I-2016 indeks harga properti komersial sebesar 191,90 atau meningkat 0,99\% (QTQ) namun melambat secara tahunan sebesar 4,15\% (YOY). Kenaikan harga bahan bangunan sebesar 31,97\% dan kenaikan upah kerja sebesar 23,58 menjadi sebab kenaikan harga properti residensial Perlambatan kenaikan harga properti tersebut akibat menurunnya permintaan terhadap hunian properti komersial. Tahun 2015 disebut-sebut sebagai titik terendah bagi pasar properti. Rata-rata pertumbuhan KPR perbankan ada di kisaran 16,5\%. Pada tahun 2014 pertumbuhan KPR perbankan masih lebih tinggi mendekati 25\% secara rata-rata. Hal ini menunjukan, bahwa sektor properti mengalami kondisi yang sulit. Hal ini perlu disikapi dengan benar oleh pelaku bisnis sektor properti agar keberlangsungan bisnis dapat terus berjalan.

Penyediaan dan kebutuhan tempat tinggal secara alamiah akan terus meningkat seiring dengan bertambahnya jumlah penduduk. Jumlah penduduk di Indonesiayang semakinmeningkat, membuatkebutuhan untuk kebutuhan rumah menjadi sangat penting. Saat ini, masih terdapat kesenjangan perumahan (backlog) antara orang yang memiliki tempat tinggal atau tidak. Kesenjangan perumahan adalah kuantitas rumah yang belum/tidak tertangani. Kesenjangan perumahan dihitung berdasarkan konsep bahwa satu unit rumah per satu rumah tangga atau kepala keluarga. Dalam menentukan acuan jumlah kesenjangan perumahan, terdapat perbedaan sudut pandang (perspektif) terhadap kesenjangan perumahan antara perspektif Kementerian Pekerjaan Umum dan Perumahan Rakyat (PUPR) dengan perspektif BPS. Dalam perspektif Kementerian PUPR, kesenjangan rumah itu terhadap rumah yang tidak layak huni, sedangkan perspektif BPS, kesenjangan rumah itu atas rumah milik. Dalam perspektif BPS, orang (rumah tangga) tinggal di rumah yang layak huni, tapi sewa, tetap dianggap perumahan. Sebaliknya menurut perspektif Kementerian PUPR, sepanjang sudah tinggal di hunian yang layak, maka tidak terhitung sebagai angka kesenjangan perumahan. Dengan adanya perbedaan tersebut, kecenderungan angka kesenjangan perumahan Kementerian PUPR lebih kecil dari BPS. Menurut data BPS jumlah kesenjangan perumahan telah mencapai 13.012.107 unit. Pada tahun 2014 menurut BPS terdapat penurunan kesenjangan pemenuhan rumah sebesar 1,02\%dari tahun 2013. Kekurangan dalam pemenuhan rumah untuk masyarakat menjadikan pangsa pasar properti sangat menguntungkan untuk berinvestasi, karena jumlah kesenjangan rumah masih cukup besar.

Tabel 1. Penyediaan dan kebutuhan rumah

\begin{tabular}{cccc}
\hline Tahun & $\begin{array}{c}\text { Jumlah } \\
\text { Rumah } \\
\text { tangga }\end{array}$ & $\begin{array}{c}\text { Kesenjangan } \\
\text { (Menghuni) }^{*}\end{array}$ & $\begin{array}{c}\text { Kesenjangan } \\
\text { (Memiliki }^{* *}\end{array}$ \\
\hline 2010 & 61.390 .300 & 7.170 .387 & 13.505 .866 \\
2011 & 62.255 .258 & 7.813 .035 & 13.216 .791 \\
2012 & 63.132 .404 & 7.310 .732 & 12.512 .842 \\
2013 & 64.021 .907 & 7.788 .086 & 13.144 .695 \\
2014 & 64.923 .944 & 7.867 .171 & 13.012 .107 \\
\hline
\end{tabular}

Keterangan: * Versi Kementerian PUPR; ** Versi BPS 
Elang Group selama ini memposisikan diri sebagai perusahaan yang berfokus pada bisnis inti sebagai pengembang perumahan rumah sehat sederhana (RSS) terus berusaha menjadi perusahaan yang kompetitif. Dengan merek Gemilang Property, Elang Group telah mengerjakan berbagai proyek pembangunan perumahan RSS di kawasan Bogor dan Sukabumi. Berdasarakan laporan tahunan internal perusahaan Elang Group, pembangunan proyek sudah berjalan sebanyak 18 proyek yang sebagian besar ditujukan untuk masyarakat kelas menengah. Elang Group sebagai perusahaan pengembang perumahan ternama di Bogor harus mampu menangkap peluang penyediaan kebutuhan rumah yang mengalami kenaikan dari tahun ke tahun.

Persaingan dari perusahaan perumahaan properti sejenis membuat perumahan properti harus mempunyai nilai lebih dibanding kompetitor lainnya. Menurut Christina dan Sudana (2013) mengatakan bahwa perencanaan strategis berbasis kinerja pada perusahaan sangat diperlukan jika perusahaan ingin tetap bertahan dalam persaingan bisnis yang semakin kompetitif. Elang Group perlu menyiapkan suatu strategi yang bisa membuat perusahaan unggul dalam persaingannya. Strategi tersebut harus direncanakan dengan sistematis agar mampu diimplementasikan pada perusahaan secara optimal sehingga bisa mencapai harapan dari pemegang saham perusahaan. Perencanaan strategis dan penilaian kinerja yang komprehensif sebagai pengganti pengukuran tradisional dicetuskan Kaplan dan Norton (2001) yaitu dengan menggunakan balanced Scorecard (BSC).

Pengukuran kinerja dan perencanaan strategis dalam kerangka BSC menggunakan beberapa perspektif yang terintegrasi, yaitu perspektif keuangan (financial perspective), perspektif pelanggan (customer perspective), perspektif proses bisnis internal (internal and process business perspective) serta perspektif pertumbuhan dan pembelajaran (learning and growth perspective). Tujuan dari penyusunan rancangan strategis berbasis balanced scorecard adalah untuk mengetahui sasaran strategis, KPI, peta strategi, target, serta inisiatif strategi yang harus dilaksanakan oleh organisasi. Salah satu kelebihan balanced scorecard menurut Niven (2002), adalah kemampuan menerjemahkan strategi menjadi aksiaksi, kemampuannya sebagai alat ukur kinerja, kemampuannya menjadi alat komunikasi strategi.

Berdasarkan latar belakang dan permasalahan yang ada maka tujuan dari penelitian ini adalah menetapkan faktor-faktor strategis dari lingkungan internal dan eksternal yang akan mempengaruhi perkembangan perusahaan Elang Group; menganalisis alternatif strategi dengan mempertimbangkan faktor-faktor internal dan eksternal yang dimiliki perusahaan Elang Group; menyusun sasaran strategis dan peta strategis yang menghubungkan antar sasaran strategis pada perusahaan Elang Group; menetapkan key performance indicator (KPI) dalam rancangan kinerja perusahaan Elang Group dengan mengunakan metode Balanced Scorecard (BSC); dan menetapkan bobot dari masingmasing perspektif BSC, dan bobot dari masing-masing KPI.

\section{METODE PENELITIAN}

Penelitian ini dilakukan di Kantor Elang Group yang beralamat di Bhumi Elang, Jalan Batu Hulung No.1 Cifor, Bogor. Penelitian ini dilakukan mulai bulan Juli 2016 hingga bulan Agustus 2016. Data yang digunakan adalah data primer dan data sekunder, baik yang berasal dari internal maupun eksternal organisasi. Data sekunder berasal dari eksternal organisasi dan studi pustaka. Data primer diperoleh melalui kuesioner, dan wawancara terstruktur dengan pihak manajemen Elang Group, dan para pakar yang relevan dengan tujuan penelitian ini. Jenis dan sumber data yang diperlukan dalam penelitian tersaji dalam Tabel 2 .

Tabel 2. Jenis dan sumber data yang diperlukan dalam penelitian

\begin{tabular}{lc}
\hline \multicolumn{1}{c}{ Jenis data } & Sumber Data \\
\hline Data primer & $\begin{array}{l}\text { Wawancara dengan responden } \\
\text { ahli }\end{array}$ \\
- Identifikasi faktor strategis internal, eksternal, sasaran strategis, serta KPI & \\
- Peta strategi & \\
- Bobot perspektif dan sasaran strategis, inisiatif strategis & Laporan tahunan dan keuangan \\
Data sekunder & Elang Group, SOP Elang Group. \\
- Data kinerja perusahaan, struktur organisasi, sejarah perusahaan,visi dan misi & \\
\hline perusahaan. & \\
\hline
\end{tabular}


Penelitian ini meruapakan penelitian kualitatif yang ditransformasi menjadi penelitian kuantitatif. Responden pada penelitian ini menggunakan istilah Informan, karena pemilihan responden pada penelitian dilakukan dengan mempertimbangkan pemahaman responden terhadap permasalahan. Jumlah responden dalam penelitian ini terdiri dari tujuh orang pakar dan praktisi dengan pertimbangan tingkat pemahaman, kompetensi dan kapasitasnya. Syarat responden yang valid, bahwa mereka adalah orang-orang yang menguasai atau ahli di bidangnya. Menurut Brojonegoro (1992), penentuan seseorang sebagai responden ahli mengacu pada orang yang benar-benar menguasai permasalahan yang diajukan, merasakan akibat dari suatu masalah atau juga kepentingan terhadap masalah tersebut. Pemilihan pakar pada penelitian ini dilakukan secara purposive sample, yakni memilih secara sengaja, bukan secara acak (random). Responden ahli dari pihak internal perusahaan antara lain: Direktur Utama/ CEO, Manajer HRD, koordinator accounting, internal audit, complience, manajer legal, dan kepala divisi kontruksi.

Data yang telah dikumpulkan perlu diolah terlebih dahulu dengan tujuan merangkum data-data yang terkumpul dari hasil wawancara dan pengisian kuesioner oleh responden ahli. Penelitian ini dibagi menjadi tiga tahap, yaitu tahap pertama berupa perumusan strategi dan tahap kedua penentuan key success factor dari Elang Group, dan yang ketiga perencangan BSC seperti nampak pada Gambar 1.

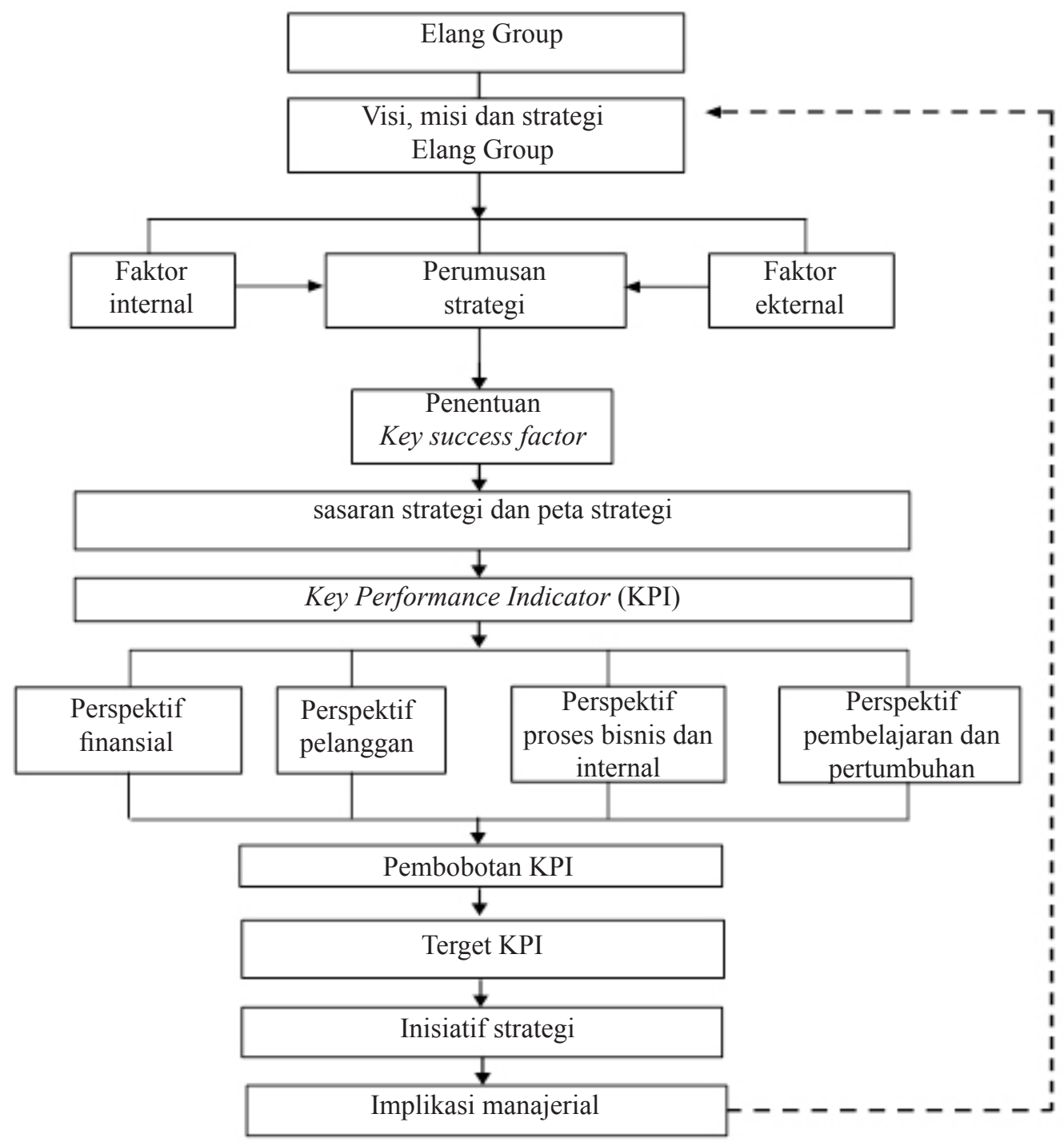

Gambar 1. Kerangka pemikiran penelitian 
Pada tahap pertama, sebelum menyusun BSC terlebih dahulu dilakukan analisis data dengan menggunakan metode analisis strength, weakness, opportunity, and threat (SWOT). Analisis SWOT dilakukan untuk menganalisa kekuatan dan kelemahan lingkungan internal dan analisa faktor peluang dan ancaman dari eksternal perusahaan. Faktor strategis internal adalah faktor-faktor kekuatan yang dapat dimanfaatkan, serta faktor-faktor kelemahan yang harus diminimalisir oleh Elang Group. Identifikasi lingkungan eksternal suatu perusahaan bertujuan untuk mengetahui peluang dan ancaman dalam wilayah bisnis perusahaan. Faktor strategis internal dan faktor strategis eksternal ditentukan berdasarkan wawancara mendalam dengan responden dari unsur manajemen.

Pada tahap kedua, dilakukan analisi key success factor (KSF). Makna dari KSF adalah bidang usaha atau kegiatan yang harus mendapatkan perhatian utama agar tujuan dan sasaran organisasi dapat tercapai (Mulyadi, 2007). Idealnya penentuan KSF diperoleh melalui proses focus group discussion (FGD) yang dilakukan secara bersama dengan seluruh responden FGD (berjumlah 8 sampai 10 orang) pada waktu dan tempat yang sama (Suhendra, 2004). Namun, pada penelitian ini penentuan KSF ditentukan melalui wawancara secara mendalam (in-depth interview) kepada responden yang telah ditetapkan sebelumnya. Hal ini dilakukan karena responden yang menjadi sumber penggalian informasi dianggap sudah cukup menguasai proses bisnis.

Analisis data pada tahap ketiga dilakukan dengan mempergunakan metode BSC dan metode paired comparison. Perumusan strategi pada tahap pertama, dan penentuan KSF pada tahap kedua kemudian diterjemahkan ke dalam keempat perspektif BSC yang dimulai dari perspektif keuangan, perspektif pelanggan, perspektif proses bisnis internal, serta yang terakhir adalah perspektif pertumbuhan dan pembelajaran (WU, 2012). Hasil dari penerjemahan strategi menghasilkan sasaran strategis (SS) untuk mewujudkan visi dan tujuan perusahaan melalui strategi yang telah dipilih. Dalam proses penerjemahan tersebut, diperhatikan hubungan sebab akibat antara keempat perspektif BSC dengan hasil rancangan scorecard yang tepat sebagai hasil akhir dari evaluasi atau review strategi perusahaan Elang Group. Setelah sasaran strategis ditentukan dari tiap perspektif, dilakukan pemetaan sasaran strategis dalam suatu panel instrumen berupa peta strategi perusahaan sesuai dengan masing-masing perspektif. Peta strategi ini dapat menggambarkan suatu kerangka hubungan sebab akibat yang dapat memperlihatkan perjalanan strategi sebuah organisasi. Model penjabaran empat perspektif BSC ini yang kemudian menentukan ukuran strategi (key performance indicator).

Menurut Kinnear dan Taylor (1996), metode paired comparison digunakan menentukan bobot setiap indicator pada keempat perspektif BSC berdasarkan tingkat kepentingan perusahaan. Penentuan bobot dilakukan dengan mengajukan identifikasi kepada narasumber ahli. Hasil pembobotan diolah dengan menggunakan metode paired comparison yang merupakan metode penentuan bobot secara sederhana dari setiap satu variabel dengan membandingkannya terhadap total seluruh bobot (Pineno, 2007). Metode ini menunjukan perbandingan nilai antara indikator (horizontal-vertikal) dalam skala 1,2,3,4 atau 5 sebagai berikut:

Nilai 1 : faktor horizontal tidak penting daripada faktor vertikal

Nilai 2 : faktor horizontal kurang penting daripada faktor vertikal

Nilai 3 : faktor horizontal sama penting daripada faktor vertikal

Nilai 4 : faktor horizontal lebih penting daripada faktor vertikal

Nilai 5 : faktor horizontal sangat penting daripada faktor vertikal

Bobot setiap indikator diperoleh dengan menentukan nilai setiap indikator terhadap nilai jumlah keseluruhan berdasarkan ketentuan rumus berikut :

$$
\left[a_{i}=\frac{x_{i}}{\sum_{i}^{n} x_{i}}\right]
$$

\section{Keterangan:}

a : bobot indikator ke-i

$\mathrm{Xi} \quad$ : nilai indikator ke-i

i : $1,2,3 . ., \mathrm{n}$

n : jumlah indikator

Pembobotan dilakukan dengan cara mewawancarai pihak responden ahli dengan panduan kuesioner. Sekelompok orang yang dimintai pendapatnya akan cenderung memberikan persepsi yang berbeda terhadap kinerja menurut pertimbangan responden ahli. 


\section{HASIL}

\section{Faktor-faktor Strategis dari Lingkungan Internal dan Eksternal}

Menurut Langkah penting yang diperlukan sebelum merumuskan strategi tingkat organisasi adalah dengan memformulasikan strategi melalui analisis dan evaluasi kekuatan dan kelemahan internal serta peluang dan ancaman eksternal perusahaan. Faktor strategis internal dan faktor strategis eksternal ditentukan berdasarkan wawancara mendalam dengan responden ahli dari unsur manajemen perusahaan Elang Group. Hasil wawancara mendalam tersebut kemudian dikumpulkan dan dikompilasi menjadi satu kesatuan yang selanjutnya akan dirumuskan menjadi strategi Elang Group dalam menghadapi persaingan di sektor properti Indonesia. Hasil identifikasi lingkungan bisnis yang dilakukan di Elang Group terdapat delapan faktor internal di perusahaan, dan lima faktor eksternal perusahaan yang berpengaruh terhadap strategi perusahaan untuk dapat bertahan dan semakin kompetitif.

Faktor internal perusahan meliputi faktor yang menjadi kekuatan dari perusahaan Elang Group, yaitu citra dari Elang Group sebagai pengembang terpercaya, harga rumah yang ditawarkan Elang Group kompetitif, dan kemudahan pembayaran cicilan rumah. Sedangkan kelemahan dari perusahaan Elang Group yaitu sistem after sales dan penanganan komplen yang belum terencana, sistem pengendalian mutu belum berjalan dengan sistematis, SOP perusahaan belum berjalan dengan konsisten, belum ada sistem penilaian kinerja perusahaan dan individu, serta belum ada pelatihan SDM yang terencana. Faktor eksternal perusahaan meliputi faktor yang menjadi peluang bagi Elang Group, yaitu prospek pengembangan properti di wilayah Bogor yang tinggi, pelonggaran kebijakan moneter Bank Indonesia, kebijakan tax amnesty, serta perkembangan teknologi informasi yang pesat. Faktor eksternal yang menjadi ancaman bagi Elang Group adalah pelemahan pertumbuhan ekonomi dunia dan Indonesia, dan inflasi yang fluktuatif.

\section{Alternatif Strategi}

Hasil analisis penggabungan faktor eksternal dan internal melalui matriks SWOT menghasilkan alternatif-alternatif strategi Elang Group, yaitu strategi S-O (Strengths-Opportunities); strategi W-O (Weaknesses-Opportunities), strategi S-T (Strenghts-
Threats); dan strategi W-T (Weaknesses-Threats). Alternatif strategi hasil analisis SWOT dapat dilihat pada Tabel 3 .

\section{Sasaran Strategis dan Peta Strategis}

Dalam suatu mata rantai nilai (value chain) produk, perlu diketahui faktor - faktor yang merupakan kunci keberhasilan atau disebut juga faktor kritis terhadap kelangsungan proses bisnis. Penentuan tiga kelompok KSF merujuk pada penelitan yang dilakukan oleh Pribadi pada tahun 1995, membagi KSF suatu perumahan dikelompokan menjadi tiga bidang utama, yakni operasional, manajemen risiko, dan pemasaran. Identifikasi KSF yang tepat dapat mempermudah organisasi dalam membuat keputusan serta menentukan variabel-variabel mana yang penting dan variabelvariabel mana yang kurang penting dalam mencapai keunggulan kompetitif (Indriartiningtias, 2010). Adapun KSF dapat dilihat pada Tabel 4.

Aulia dan Ikhwana (2010) mengatakan bahwa penggunaan BSC dapat dilakukan untuk merencanakan dan merumuskan strategi pengembangan usaha dengan tidak melupakan kapasitas dari perusahaan itu sendiri. Dalam perancangan BSC hal yang harus dilakukan pertama kali adalah menetapkan sasaran strategis yang ingin dicapai oleh suatu perusahaan. Proses identifikasi sasaran strategis dilakukan dengan penjabarann berdasarkan alternatif strategi yang telah diformulasikan analisis SWOT seperti dapat dilihat pada Tabel 5. Hasil dari analisis SWOT digunakan untuk sasaran strategis yang bersifat pengungkit (enabler). Menurut Walsh (2006), sasaran strategik sebaiknya menunjukan upaya perbaikan dari kondisi saat ini, menuju kondisi ideal yang diinginkan oleh perusahaan.

Setelah sasaran strategis dirumuskan, tahapan selanjutnya adalah membuat peta strategi. Tujuan dari pemetaan sasaran strategi adalah untuk menjabarkan strategi secara visual, melalui sejumlah sasaran strategis yang terangkai dalam hubungan sebab akibat, sehingga memudahkan komunikasi strategi. Menurut Kaplan dan Norton (2004), di dalam peta strategi, secara eksplisit visi diterjemahkan ke dalam empat perspektif, yaitu keuangan, pelanggan, proses bisnis internal serta perspektif pembelajaran dan pertumbuhan. Masingmasing perspektif menunjukkan peta teritori regional yang memiliki hubungan sebab akibat dengan perspektif lainnya (Walsh, 2006). Hasil wawancara serta studi dokumen pada Elang Group maka pada peta strategi 
Elang Group ini, perspektif yang dijadikan landasan adalah perspektif pembelajaran dan pertumbuhan, kemudian dilanjutkan dengan perspektif keuangan, lalu perspektif proses bisnis internal, hingga perspektif pelanggan dan keuangan sebagai perspektif terakhir. Peta sasaran strategi menghubungkan pencapaian strategi perusahaan melalui sasaran-sasaran strategisnya bersama-sama dalam rantai sebab akibat berdasarkan ke empat perspektif BSC. Armitage dan Scholey (2003), peta strategi dapat digunakan untuk menggambarkan, mengkomunikasikan, menguji asumsi-asumsi, dan mengukur kemajuan sasaran strategik suatu organisasi. Peta strategi perusahaan Elang Group dapat dilihat pada Gambar 2.

\section{Key Performance Indicators (KPI)}

Setelah tahapan penyusunan peta strategi dilakukan, tahap selanjutnya adalah mengidentifikasi key performance indicators (KPI) sebagai indikator keberhasilan dari tiap sasaran strategis. Penyusunan KPI ini diharapkan dapat membantu penilaian terhadap tingkat efisiensi dan efektivitas beberapa aktivitas utama di perusahaan dengan maksud untuk mengembangkan rencana kerja untuk proses pembelajaran serta perbaikan (Wibowo dan Muslim, 2010). Rincian hasil identifikasi dan analisis KPI Elang Group pada Tabel 6.

Tabel 3. Matrik analisis SWOT

\begin{tabular}{|c|c|c|}
\hline & $\begin{array}{l}\text { Strengths (S) } \\
\text { 1. Brand image Elang Group sebagai } \\
\text { pengembang terpercaya } \\
\text { 2. Harga rumah yang ditawarkan } \\
\text { Elang Group kompetitif } \\
\text { 3. Kemudahan pembayaran cicilan } \\
\text { rumah }\end{array}$ & $\begin{array}{l}\text { Weaknesses }(\mathbf{W}) \\
\text { 1. Sistem after sales dan penanganan } \\
\text { complain yang belum terencana } \\
\text { 2. Sistem pengendalian mutu belum } \\
\text { berjalan deng an sistematis } \\
\text { 3. SOP perusahaan belum berjalan } \\
\text { dengan konsisten belum ada sistem } \\
\text { penilaian kinerja perusahaan dan } \\
\text { individu (KPI) } \\
\text { 4. Belum ada pelatihan SDM yang } \\
\text { terencana }\end{array}$ \\
\hline $\begin{array}{l}\text { Opportunities }(\mathbf{O}) \\
\text { 1. Prospek pen gembanran properti di } \\
\text { wilayah Bogor yang tinggi } \\
\text { 2. Pelonggaran kebijakan moneter } \\
\text { Bank Indonesia } \\
\text { 3. Kebijakan tax amnesty } \\
\text { 4. Perkemban ran telmologi informasi } \\
\text { yang pesat }\end{array}$ & $\begin{array}{l}\text { Strategi S-O } \\
\text { 1. Melakukan program markerting } \\
\text { campaign yang sistematis (S1,S2,S3- } \\
\text { O1,O2,O3) } \\
\text { 2. Mengembangkan lokasi perumahan } \\
\text { ke daerah potensial (S1,S2,S3- } \\
\text { O1,O2,O3) } \\
\text { 3. Melakukan adaptasi teknologi IT } \\
\text { (S1-O 1,O2,O3,O4) }\end{array}$ & $\begin{array}{l}\text { Strategi W-O } \\
\text { 1. Membuat sistem customer } \\
\text { relationship management yang prima } \\
(\mathrm{W} 1, \mathrm{~W} 3-\mathrm{O} 1, \mathrm{O} 2, \mathrm{O} 3) \\
\text { 2. Membuat sistem manajemen mutu } \\
\text { proyek yang terpadu (W2,W3,W4- } \\
\text { O1,O2,O3) } \\
\text { 3. Merancang sistem manajemen SDM } \\
\text { yang bandal (W4,W5- O1,O2,O3) }\end{array}$ \\
\hline $\begin{array}{l}\text { Threats }(\mathbf{T}) \\
\text { 1. Pelemahan pertumbuhan ekonomi } \\
\text { dunia dan Indonesia } \\
\text { 2. Inflasi yang fluktuatif }\end{array}$ & $\begin{array}{l}\text { Strategi S-T } \\
\text { 1. Melakukan diversifikasi produk } \\
\text { properti Elang Group (S1,S3-T1,T2) } \\
\text { 2. Membangun aliansi strategis dengan } \\
\text { perusahaan pengembang lain (S1,S2- } \\
\text { T1,T2) } \\
\text { 3. Merancang anggaran dan biaya } \\
\text { proyek yang efisien }(\mathrm{S} 1, \mathrm{~S} 2-\mathrm{T} 1, \mathrm{~T} 2)\end{array}$ & $\begin{array}{l}\text { Strategi W-T } \\
\text { 1. Melakukan program upgrading } \\
\text { kompe tensi tenaga pemasaran (W5- } \\
\text { T1,T2) } \\
\text { 2. Menerapkan sistem GCG yang } \\
\text { akuntabel (W1,W2,W3-T1,T2) }\end{array}$ \\
\hline
\end{tabular}

Tabel 4. Key success factor Elang Group

\begin{tabular}{ll}
\hline \multicolumn{1}{c}{ Area Key Success Faktor } & \multicolumn{1}{c}{ Key Success Factor } \\
\hline Operasional & 1. Budgeting rencana anggaran dan biaya \\
& 2. Manajemen mutu \\
& 3. Adaptasi teknologi terbaru \\
& 4. Penerapan standard operating procedure \\
Manajemen risiko & 1. Penerapan good corporate governance \\
& 2. Internal control \\
Pemasaran & 1. Kepuasan pelanggan \\
& 2. Aktivitas promosi \\
& 3. Kualitas SDM \\
\hline
\end{tabular}


Tabel 5. Sasaran strategis Elang Group

\begin{tabular}{ll}
\hline \multicolumn{1}{c}{ Perspektif } & \multicolumn{1}{c}{ Sasaran strategis } \\
\hline Finansial & 1. Meningkatkan long term shareholder value \\
& 2. Meningkatnya pendapatan Elang Group \\
& 3. Meningkatkan efisiensi biaya \\
Konsumen & 1. Meningkatkan kepuasan pelanggan \\
& 2. Terwujudnya sistem customer relationship management yang prima \\
& 3. Meningkatkan kerja sama strategis dengan perusahan pengembang lain \\
Bisnis internal & 1. Terciptanya produk properti Elang yang sesuai value proposisi konsumen \\
& 2. Terciptanya rencana anggaran dan biaya proyek yang efisien \\
& 3. Mengembangkan sistem manajemen mutu proyek yang terpadu \\
& 4. Mengembangkan program pemasaran yang sistematis \\
& 5. Meningkatkan kompetensi tenaga pemasaran \\
& 6. Meningkatkan efektivitas Implementasi GCG dan manajemen risiko \\
Pertumbuhan dan pembelajaran & 1. Meningkatkan pengelolaan kinerja SDM Elang Group yang efektif \\
& 2. Meningkatkan kualitas SDM Elang Group yang kompeten \\
& 3. Mengoptimalkan penggunaan teknologi untuk menunjang operasional perusahaan \\
\hline
\end{tabular}

\section{VISI Elang Group: "Menjadi perusahaan pembangunan ekonomi bangsa yang berkarakter,} berkeadilan dan menjadi aset serta kebangga bangsa Indonesia"

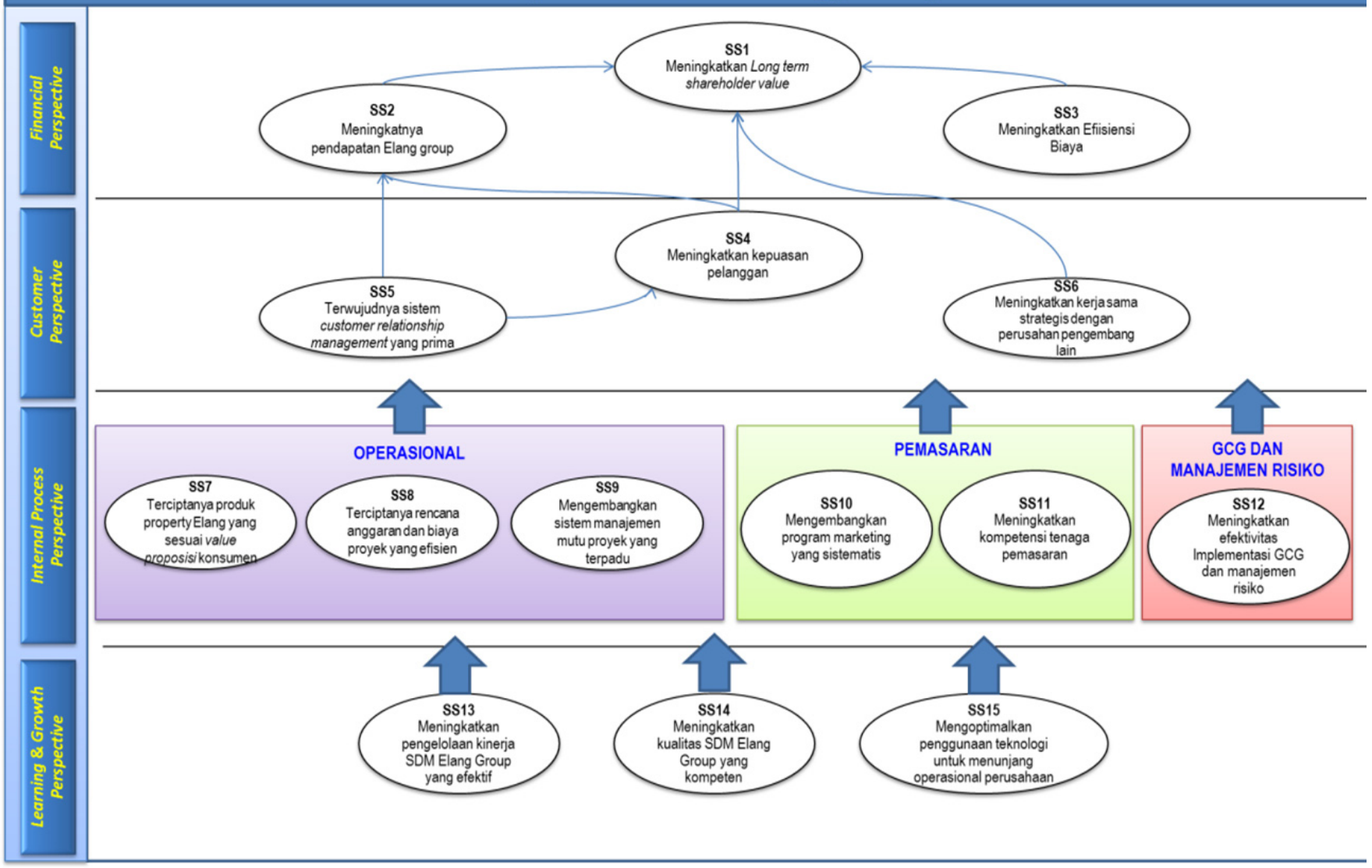

Gambar 2. Peta strategi Elang Group 
Tabel 6. Key performance indicators Elang Group

\begin{tabular}{|c|c|c|}
\hline Perspektif & Sasaran strategis & Key performance indicators \\
\hline \multirow[t]{4}{*}{ Finansial } & Meningkatkan Long term shareholder value. & $\begin{array}{l}\text { F1. Return on Investment (ROI) } \\
\text { F2. Debt to Equity Ratio (DER) }\end{array}$ \\
\hline & Meningkatnya pendapatan Elang group. & F3. Persentase Pertumbuhan revenue \\
\hline & & F4. Persentase Pertumbuhan penjualan unit rumah \\
\hline & Meningkatkan efisiensi biaya & F5. Operating Expense Ratio (OER) \\
\hline \multirow[t]{4}{*}{ Konsumen } & Meningkatkan kepuasan pelanggan & $\begin{array}{l}\text { K1. Persentase pelanggan yang puas dengan } \\
\text { produk dan layanan Elang group }\end{array}$ \\
\hline & & $\begin{array}{l}\text { K2. Persentase peningkatan market share } \\
\text { K3. Net Promoter Score }\end{array}$ \\
\hline & $\begin{array}{l}\text { Terwujudnya sistem customer relationship } \\
\text { management yang prima }\end{array}$ & $\begin{array}{l}\text { K4. Jumlah keluhan pelanggan/ tahun } \\
\text { K5. Rata-rata lama penyelesaian permintaan/kelu- } \\
\text { han dari customer }\end{array}$ \\
\hline & $\begin{array}{l}\text { Meningkatkan kerja sama strategis dengan } \\
\text { perusahan pengembang lain }\end{array}$ & K6. Jumlah Kerja sama per tahun \\
\hline \multirow[t]{8}{*}{ Bisnis Internal } & $\begin{array}{l}\text { Terciptanya produk properti Elang yang } \\
\text { sesuai value proposisi konsumen }\end{array}$ & $\begin{array}{l}\text { B1. Persentase pertumbuhan proyek/ tahun } \\
\text { B2. Luas land bank (dalam hektar) }\end{array}$ \\
\hline & $\begin{array}{l}\text { Terciptanya rencana anggaran dan biaya } \\
\text { proyek yang efisien }\end{array}$ & $\begin{array}{l}\text { B3. Project Cost Variance } \\
\text { B4. Project Schedule Variance }\end{array}$ \\
\hline & $\begin{array}{l}\text { Mengembangkan sistem manajemen mutu } \\
\text { proyek yang terpadu }\end{array}$ & $\begin{array}{l}\text { B5. Persentase projek properti yang diselesaikan } \\
\text { tepat waktu sesuai rencana }\end{array}$ \\
\hline & & B6. Jumlah kerusakan atau cacat/ project \\
\hline & $\begin{array}{l}\text { Mengembangkan program marketing yang } \\
\text { sistematis }\end{array}$ & $\begin{array}{l}\text { B7. Jumlah program marketing/tahun } \\
\text { B8. Return of Marketing Invesment }\end{array}$ \\
\hline & Meningkatkan kompetensi tenaga pemasaran & B9. Persentase sales closing \\
\hline & $\begin{array}{l}\text { Meningkatkan efektivitas Implementasi GCG } \\
\text { dan manajemen risiko }\end{array}$ & $\begin{array}{l}\text { B10. Tingkat coverage SOP terhadap seluruh } \\
\text { pekerjaan }\end{array}$ \\
\hline & & B11. Jumlah temuan Audit internal \\
\hline \multirow[t]{3}{*}{ Pembelajaran } & $\begin{array}{l}\text { Meningkatkan pengelolaan kinerja SDM } \\
\text { Elang Group yang efektif }\end{array}$ & P1. Persentase karyawan yang puas bekerja \\
\hline & $\begin{array}{l}\text { Meningkatkan kualitas SDM Elang Group } \\
\text { yang kompeten }\end{array}$ & $\begin{array}{l}\text { P2. Jumlah pelatihan yang diterima karyawan/ } \\
\text { tahun }\end{array}$ \\
\hline & $\begin{array}{l}\text { Mengoptimalkan penggunaan teknologi untuk } \\
\text { menunjang operasional perusahaan }\end{array}$ & $\begin{array}{l}\text { P3. Jumlah visitor yang melakukan kunjungan ke } \\
\text { website perusahaan }\end{array}$ \\
\hline
\end{tabular}

Perancangan KPI ditetapkan KPI sebanyak 25 KPI yang terbagi dalam empat perspektif BSC. Pada perspektif finansial, yakni return on investment (ROI), debt to equity ratio (DER), persentase pertumbuhan revenue, persentase pertumbuhan penjualan unit rumah, operating expense ratio (OER). Perspektif konsumen, untuk indikator kinerja utama/KPI meliputi persentase pelanggan yang puas dengan produk dan layanan Elang group, persentase peningkatan market share, net promoter score, jumlah keluhan pelanggan/ tahun, dan rata-rata lama penyelesaian permintaan/keluhan dari customer. Sebaliknya, untuk KPI perspektif bisnis internal meliputi persentase pertumbuhan proyek/ tahun, luas landbank (dalam hektar), project cost variance, project schedule variance, persentase projek properti yang diselesaikan tepat waktu sesuai rencana, jumlah kerusakan atau cacat/project, jumlah program marketing/tahun, return of marketing invesment, persentase sales closing, tingkat coverage SOP terhadap seluruh pekerjaan, dan Jumlah temuan audit internal. Pada persepektif pembelajaran dan pertumbuhan memiliki KPI adalah persentase karyawan yang puas bekerja, jumlah pelatihan yang diterima karyawan/ tahun, jumlah visitor yang melakukan kunjungan ke website perusahaan. 


\section{Bobot dari Masing-masing Perspektif Balance Scorecard dan KPI}

Setelah menentukan KPI, sebelum beralih ke langkah selanjutnya, yakni penentuan target dan inisiatif strategis, terlebih dahulu dilakukan pembobotan dari tiap perspektif BSC serta KPI. Tujuan dari tahapan ini adalah untuk melihat seberapa besar bobot dari tiap perspektif maupun KPI terhadap keseluruhan kinerja. Tabel hasil pembobotan dari perspektif BSC beserta KPI dapat dilihat pada Tabel 7.

Pada perspektif finansial didapatkan bobot ratarata KPI tertinggi untuk return on investment (ROI) sebesar 41,4\%. Pembobotan KPI juga dilakukan pada perspektif konsumen, untuk indikator kinerja utama yang mendapat persentase atau bobot rata-rata tertinggi adalah persentase pelanggan yang puas dengan produk dan layanan Elang group sebesar 37,3\% yang ini berarti manajemen Elang Group dapat memfokuskan diri untuk terlebih dahulu memenuhi pencapaian KPI ini. Pada perspektif proses bisnis internal, untuk indikator kinerja utama yang mendapat bobot rata-rata tertinggi adalah pertumbuhan proyek baru, dengan bobot sebesar 20,7\%. Pembobotan KPI pada perspektif pembelajaran dan pertumbuhan didapatkan bobot rata-rata KPI tertinggi untuk persentase karyawan yang puas bekerja sebesar $42,6 \%$.

Tabel 7. Pembobotan perspektif BSC dan KPI

\begin{tabular}{|c|c|c|}
\hline Perspektif & $\begin{array}{c}\text { Bobot } \\
\text { rata-rata (\%) }\end{array}$ & $\begin{array}{c}\text { Bobot terhadap } \\
\text { seluruh kinerja (\%) }\end{array}$ \\
\hline Keuangan & & 47,6 \\
\hline F1. Return on Investment (ROI) & 41,4 & 19,7 \\
\hline F2. Debt to Equity Ratio (DER) & 23,0 & 10,9 \\
\hline F3. Persentase Pertumbuhan revenue & 16,9 & 8,0 \\
\hline F4. Persentase Pertumbuhan penjualan unit rumah & 11,3 & 5,4 \\
\hline F5. Operating Expense Ratio (OER) & 7,3 & 3,5 \\
\hline Konsumen & & 29,9 \\
\hline K1. Persentase pelanggan yang puas dengan produk dan layanan Elang group & 37,3 & 11,2 \\
\hline K2. Persentase peningkatan market share & 21,7 & 6,5 \\
\hline K3. Net Promoter score & 16,2 & 4,8 \\
\hline K4. Jumlah keluhan pelanggan/tahun & 13,6 & 4,1 \\
\hline K5. Rata-rata lama penyelesaian permintaan/keluhan dari customer & 8,3 & 2,5 \\
\hline K6. Jumlah kerja sama per tahun & 2,8 & 0,8 \\
\hline Proses Bisnis Internal & & 14,6 \\
\hline B1. Persentase pertumbuhan proyek/tahun & 20,7 & 3,0 \\
\hline B2. Luas landbank (dalam hektar) & 9,9 & 1,4 \\
\hline B3. Project Cost Variance & 17,5 & 2,6 \\
\hline B4. Project Schedule Variance & 11,5 & 1,7 \\
\hline B5. Persentase projek properti yang diselesaikan tepat waktu sesuai rencana & 8,1 & 1,2 \\
\hline B6. Jumlah kerusakan atau cacat/project & 6,3 & 0,9 \\
\hline B7. Jumlah program marketing/tahun & 5,5 & 0,8 \\
\hline B8. Return of Marketing Invesment & 6,1 & 0,9 \\
\hline B9. Persentase Sales Closing & 4,9 & 0,7 \\
\hline B10. Tingkat coverage SOP terhadap seluruh pekerjaan & 4.3 & 0,6 \\
\hline B11. Jumlah temuan audit internal & 5,0 & 0,7 \\
\hline Pembelajaran dan Pertumbuhan & & 7,8 \\
\hline P1. Persentase karyawan yang puas bekerja & 42,6 & 3,3 \\
\hline P2. Jumlah pelatihan yang diterima karyawan/tahun & 32,3 & 2,4 \\
\hline P3. Jumlah visitor yang melakukan kunjungan ke website perusahaan & 25,1 & 1,9 \\
\hline
\end{tabular}


Dalam mengukur keberhasilan pencapaian sasaran strategik serta KPI yang telah ditetapkan sebelumnya, organisasi memerlukan penentuan target. Target merupakan ukuran yang ingin dicapai dalam kurun waktu tertentu. Suatu target harus disepakati oleh semua pihak yang terlibat (Bostan, 2012). Dalam penelitian ini, target dari masing-masing KPI tidak ditentukan besarannya dan penentuannya diserahkan kepada manajemen Elang Group. Dalam penelitian ini direkomendasikan besaran atau ukuran dari target KPI untuk mempermudah pihak manajemen Elang Group dalam menentukan target yang sesuai. Setelah target KPI dari masing-masing sasaran strategis ditentukan, langkah selanjutnya menentukan merumuskan inisiatif strategis. Inisiatif strategis merupakan suatu kegiatan atau beberapa langkah kegiatan yang digunakan untuk mencapai target KPI. Pada penelitian ini, perumusan inisiatif strategis pada masing-masing sasaran strategis terdiri dari satu atau lebih inisiatif strategis sesuai dengan kondisi dan kebutuhan pencapaian target KPI. Target dan inisiatif strategis dapat dilihat pada Tabel 8 .

Tabel 8. Sasaran strategis, KPI, target, dan inisiatif strategis

\begin{tabular}{|c|c|c|c|}
\hline \multirow[b]{2}{*}{ Sasaran strategis } & \multicolumn{2}{|r|}{ Target*) } & \multirow[b]{2}{*}{ Inistiatif strategis } \\
\hline & KPI & $\begin{array}{c}\text { Dis- } \\
\text { kriptif }\end{array}$ & \\
\hline
\end{tabular}

\section{Perspektif Keuangan}

Meningkatkan long term shareholder value

Meningkatnya pendapatan Elang group

Meningkatkan efisiensi biaya

\section{Perspektif Konsumen}

Meningkatkan kepuasan pelanggan

Terwujudnya sistem customer relationship management yang prima

Meningkatkan kerja sama strategis dengan perusahan pengembang lain

\section{Perspektif Bisnis Internal}

Terciptanya produk properti Elang yang sesuai value proposisi konsumen

Terciptanya rencana anggaran dan biaya proyek yang efisien

Mengembangkan sistem manajemen mutu proyek yang terpadu
F1 + Angka - Melakukan evaluasi pengeluaran berdasarkan past performance dan

F2 _ Angka proyeksi kebutuhan investasi Elang Group

- Mebuat perencanaan proyek yang akan dilaksanakan per tahun

$\mathrm{F} 3+\% \quad-$ Melakukan aktivitas prmosi dengan menggunakan semua chanell promisi

$\mathrm{F} 4 \quad+\quad \% \quad$ yang dimungkinkan seperti (website, email marketing, sosmed dil)

- Mengikuti expo properti yang diadakan oleh pihak kedua (asosiasi/bank pemberi KPR)

- Melakukan program promosi member get member

F5 $\quad-/=\quad$ Angka - Mengendalikan dan memantau anggaran dana kompreherensif

- Melakukan efesiensi dengan tetap memperhatikan kualitas produk

$\mathrm{K} 1+\% \quad$ - Membangun database pelanggan berbasis CRM

$\mathrm{K} 2+\% \quad-$ Melakukan customer gathering dengan calon pembeli properti/existing

$\mathrm{K} 3+$ Angka konsuemen untuk melakukan cross-selling atau up-selling

Angka - Membentuk komunitas pelanggan, komunitas yang terbentukini akan berguna untuk menjaga loyalitas

K4 - Angka - Membuat divisi customer service untuk layanan Elang Group

K5 - Hari - Membuat blueprint standart layanan penanganan komplain atau permintaan dari konsumen

- Komunikasikan standart yang telah dibuat kepada setiap karyawan, terutama front-line

K6 + Angka - Membuat MoU dengan pengembang lain

B1 $+\quad \% \quad-$ Melakukan pengembangan dan perluasan proyek berdasarkan tren dan

$\mathrm{B} 2+$ ha riset pasar. Pengembangan tidak hanya terkait segmentasi tapi juga pemilihan lokasi

B3 ** Angka - Elang Group Harus membuat, mendokumentasikan, menerapkan, dan

B4 *** Angka memelihara sistem manajemen mutu dan melakukan peningkatan berkelanjutan secara efektif sesuai dengan persyaratan standar ISO 2009:2008

B5 $\quad+\quad \% \quad-$ Melakukan pembinaan dan pengawasan on the spot (site visit)

- Meningkatkan pengawasan terhadap pelaksanaan

Keterangan: (+) Meningkat dari tahun lalu; (-) Lebih rendah dari tahun lalu, (-/=)Lebih rendah/sama dari posisi tahun lalu

(*) Penentuan besaran target yang ingin dicapai dari KPI ditentukan oleh manajemen Elang Group

(**) Budgeted Cost for Work Performed (BCWP) > Actual Cost of Work Performed (ACWP)

(***) BCWP > Budgeted Cost for Work Scheduled (BCWS) 


\section{Implikasi Manajerial}

Penjabaran implikasi manajerial didasarkan pada empat perspektif dalam BSC yang tertuang dalam pembahasan sebelumnya. Setelah manajemen Elang Group mengetahui hal tersebut, maka Elang Group dapat melaksanakan beberapa hal penting yang dapat mendukung pencapaian visi dan misi organisasi melalui penerapan BSC. Berdasarkan hasil analisis dan pembahasan mengenai perencanaan strategis pengembangan sistem penilaian kinerja berbasis BSC di Elang Group maka selanjutnya dapat disusun langkah-langkah untuk proses implementasi.

Pada fase pertama, implementasi BSC dilakukan pada level perusahaan. Proses implementasi ini dilaksanankan mulai dari bulan Januari - Februari 2017. Beberapa langkah yang dapat diterapkan antara lain, 1) melakukan FGD antara CEO, dan semua corporate officer Elang group untuk finalisasi BSC di level perusahaan Elang Group. 2) menetapkan BSC, KPI, dan target 2017. 3) setelah BSC level perusahaan ditetapkan, maka langkah selanjutnya adalah melakukan sosialisasi BSC, sekaligus penandatanganan kontrak kinerja. 4) pengembangan manual KPI untuk mempermudah proses perhitungan KPI. 5) selanjutnya semua hal yang telah dilakukan proses reporting ke share holder Elang Group dalam quarterly meeting pertama pada tahun 2017.

Pada fase kedua, implementasi BSC dilakukan pada level departemen. Proses implementasi ini dilaksanankan mulai dari bulan April - Juli 2017. Beberapa langkah yang dapat diterapkan antara lain, 1) melakukan wawancara dengan semua kepala department untuk menentukan sasaran strategis dari masing-masing departemen, dan peta strategis pada depatemen yang bersangkutan. 2) setelah BSC di level departemen terbentuk, maka dilakukan finalisasi BSC antar departemen dan singkronisasi dengan BSC level perusahaan. Konsep ini dikenal dengan nama metode cascading dan vertical alignment dalam persepektif BSC. 4) pengembangan manual KPI untuk mempermudah proses perhitungan KPI. 5) selanjutnya semua hal yang telah dilakukan proses reporting ke share holder Elang Group dalam quarterly meeting ke dua pada tahun 2017.

Pada fase ketiga, implementasi BSC dilakukan pada level departemen. Proses implementasi ini dilaksanankan mulai dari bulan Juli - oktober 2017.
Beberapa langkah yang dapat diterapkan antara lain, 1) melakukan horizontal alignment dengan department terkati untuk menentukan pembagian KPI. 2) bekerja sama dengan HRD untuk menyusun indivual scorecard untuk penilaian indvidu. 3) setelah BSC level perusahaan ditetapkan, maka langkah selanjutnyaadalah melakukan sosialisasi BSC untuk level departemen dan sistem penilaian kinerja individu. 4) dilakukan proses reporting ke share holder Elang Group dalam quarterly meeting ketiga pada tahun 2017.

Pada fase keempat, implementasi BSC dilakukan penerapan BSC secara menyeluruh. Proses implementasi ini dilaksanankan mulai dari bulan November - Desember 2017. Beberapa langkah yang dapat diterapkan antara lain,1) melkaukan penerapan BSC pada level perusahaan, departemen, dan individu. 2) proses penerapan BSC adalah proses perbaikan dan review yang berkesinambungan dapat dilakukan di akhir tahun 2017, untuk mempersiapkan BSC untuk tahun berikutnya. 3) proses reporting ke share holder Elang Group dalam quarterly meeting ke-empat pada tahun 2017.

Pembenahan sistem penilaian kinerja yang ada sehingga hasil penilaian kinerja dapat menjadi sarana yang tepat bagi organisasi untuk memantau kinerja organisasi, terutama kinerja para karyawan yang menjadi motor utama penggerak kegiatan bisnis. Setelah perusahaan Elang Group mengetahui hal tersebut maka organisasi dapat melaksanakan beberapa hal penting yang dapat terus mendukung pencapaian visi dan misi organisasi melalui penerapan BSC.

\section{KESIMPULAN DAN SARAN}

\section{Kesimpulan}

Dari hasil penelitian yang dilakukan di Elang Group maka didapatkan simpulan sebagai berikut hasil identifikasi lingkungan bisnis yang dilakukan di Elang Group terdapat delapan faktor internal di perusahaan, dan lima faktor external perusahaan yang berpengaruh terhadap strategi perusahaan untuk dapat bertahan dan semakin kompetitif. Faktor internal perusahan meliputi faktor yang menjadi kekuatan dari perusahaan Elang group, yaitu citra, harga rumah, dan kemudahan pembayaran cicilan rumah. Kelemahan dari perusahaan Elang Group, yaitu sistem after sales dan penanganan komplen yang belum terencana, sistem pengendalian 
mutu belum berjalan dengan sistematis, SOP perusahaan belum berjalan dengan konsisten, belum ada sistem penilaian kinerja perusahaan dan individu, serta belum ada pelatihan SDM yang terencana. Faktor eksternal perusahaan meliputi faktor yang menjadi peluang bagi Elang Group yaitu prospek pengembangan properti di wilayah Bogor yang tinggi, pelonggaran kebijakan moneter Bank Indonesia, kebijakan tax amnesty, serta perkembangan teknologi informasi yang pesat. Sedangkan faktor eksternal yang menjadi ancaman bagi Elang Group adalah pelemahan pertumbuhan ekonomi dunia dan Indonesia, dan inflasi yang fluktuatif.

Terdapat empat alternatif strategi yang dapat dilakukan oleh Elang Group dalam meningkatkan kinerjanya. Strategi pertama adalah Strategi SO yakni melakukan program marketing campaign yang sistematis. Strategi kedua mengembangkan lokasi perumahan ke daerah potensial, sedangkan strategi ketiga yaitu melakukan adaptasi teknologi IT. Sedangkan strategi ST yaitu melakukan diversifikasi produk properti Elang Group. Strategi ST yang kedua membangun aliansi strategis dengan perusahaan pengembang lain. Sedangkan strategi ST yang ketiga adalah merancang anggaran dan biaya proyek yang efisien. Selain strategi yang berfokus pada pemanfaatan peluang, strategi bersaing lainya yakni strategi WO dan WT. Strategi WO meliputi pembuat sistem customer relationship management yang prima, membuat sistem manajemen mutu proyek yang terpadu, dan terakhir adalah dengan merancang sistem manajemen SDM yang handal. Strategi WT meliputi melakukan program upgrading kompetensi tenaga pemasaran, serta menerapkan sistem GCG yang akuntabel.

Terdapat 15 sasaran strategis (SS), yakni SS1. Meningkatkan long term shareholder value; SS2. Meningkatnya pendapatan Elang group; SS3. Meningkatkan efisiensi biaya; SS4. Meningkatkan kepuasan pelanggan; SS5. Terwujudnya sistem customer relationship management yang prima; SS6. Meningkatkan kerja sama strategis dengan perusahan pengembang lain; SS7. Terciptanya produk properti Elang yang sesuai value proposisi konsumen; SS8. Terciptanya rencana anggaran dan biaya proyek yang efisien; SS9.Mengembangkan sistem manajemen mutu proyek yang terpadu; SS10. Mengembangkan program marketing yang sistematis; SS11. Meningkatkan kompetensi tenaga pemasaran; SS12. Meningkatkan efektivitas Implementasi GCG dan manajemen risiko;
SS13.Meningkatkan pengelolaan kinerja SDM Elang Group yang efektif; SS14.Meningkatkan kualitas SDM Elang Group yang kompeten; SS15. Mengoptimalkan penggunaan teknologi untuk menunjang operasional perusahaan.

Perancangan KPI ditetapkan KPI sebanyak 25 KPI yang terbagi dalam empat perspektif BSC. Pada perspektif finansial yakni ROI, DER, persentase pertumbuhan revenue, persentase pertumbuhan penjualan unit rumah, OER. Perspektif konsumen, meliputi persentase pelanggan yang puas dengan produk dan layanan Elang group, persentase peningkatan market share, net promoter score, jumlah keluhan pelanggan/ tahun, dan rata-rata lama penyelesaian permintaan/keluhan dari customer. KPI perspektif bisnis internal meliputi Persentase pertumbuhan proyek/ tahun, luas landbank (dalam hektar), project cost variance, project schedule variance, persentase projek properti yang diselesaikan tepat waktu sesuai rencana, jumlah kerusakan atau cacat/ project, jumlah program marketing/tahun, return of marketing invesment, persentase sales closing, tingkat coverage SOP terhadap seluruh pekerjaan, dan jumlah temuan audit internal. Pada persepektif pembelajaran dan pertumbuhan KPInya adalah persentase karyawan yang puas bekerja, jumlah pelatihan yang diterima karyawan/tahun, jumlah visitor yang melakukan kunjungan ke website perusahaan.

Perspektif finansial didapatkan bobot rata-rata KPI tertinggi untuk ROI sebesar 41,4\%. Pembobotan KPI juga dilakukan pada perspektif konsumen, untuk indikator kinerja utama yang mendapat persentase atau bobot rata-rata tertinggi adalah persentase pelanggan yang puas dengan produk dan layanan Elang group sebesar 37,3\% yang ini berarti manajemen Elang Group dapat memfokuskan diri untuk terlebih dahulu memenuhi pencapaian KPI ini. Pada perspektif proses bisnis internal, untuk indikator kinerja utama yang mendapat bobot rata-rata tertinggi adalah pertumbuhan proyek baru, dengan bobot sebesar 20,7\%. Sedangkan untuk pembobotan KPI pada perspektif pembelajaran dan pertumbuhan didapatkan bobot rata-rata KPI tertinggi untuk persentase karyawan yang puas bekerja sebesar $42,6 \%$.

\section{Saran}

Beberapa hal yang dapat disampaikan sebagai saran kepada manajemen Elang Group dalam meningkatkan kinerja yang dihasilkan, yaitu dalam 
upaya meningkatkan ROI, Elang Group dapat melakukan penambahan penjualan yang nantinya akan meningkatkan revenue harus diimbangi dengan pengendalian terhadap arus kas masuk dan arus kas keluar. Salah satu cara dalam meningkatkan proses pemasaran adalah dengan membangun hubungan yang erat dengan pelanggan. Kedepannya diharapkan pelanggan property dari Elang Group dapat memberikan promosi word of mouth yang baik. Perlu dilakukan simulasi pengukuruan kinerja atas strategi yang dilakukan dengan menggunakan teknik pewarnaan dan rataan skor, sehingga akan didapatkan gambaran yang jelas terkait kinerja berdasarkan dari masing - masing KPI yang telah dicapai saat ini. Sebagai referensi untuk penelitian lebih lanjut, dapat dilakukan proses cascading atau penurunan KPI sampai tingkat divisi hingga tingkat individu agar organisasi mendapatkan indikator penilaian yang dapat berlaku sampai tingkat operasional organisasi.

\section{DAFTAR PUSTAKA}

BPS. 2015. Laporan Pertumbuhan Ekonomi Indonesia. Jakarta: BPS.

Bostan I. 2012. The balanced scorecard (BSC) implications on the increase of public companies performance. African Journal of Business Management 6(22): 6465-6470.

Brojonegoro, Bambang PS. 1992. AHP (The Analytic Hierarchy Process). Jakarta: Pusat Antar University-Studi Ekonomi Universitas Indonesia.

Christina NPY, Sudana IP. 2013. Penilaian kinerja pada PT Adhi karya dengan pendekatan balanced Scorecard. E-Jurnal Akuntansi Universitas Udayana 5(3): 516-529.

Dewi A, Ikhwana A. 2012. Perencanaan strategi pengembangan usaha kain tenun sutra dengan pendekatan metode balanced Scorecard. Jurnal Riset Manajemen 10(1): 46.

Indriartiningtias, Retno. 2010. Perbaikan kualitas pelayanan PT. Pos Indonesia cabang sadang serang. Jurnal Teknik Industri 2: 30-38.

Kaplan, Robert S, Norton D. 2001. The Strategy Focused Organization: How Balanced Scorecard Companies Thrive in The New Bussiness Environment. Massachusetts: Harvard Business School Press.

Kaplan, Robert S, Norton D. 2004. Strategy Maps: Converting Intangible Assets Into Tangible Outcomes. Massachusetts: Harvard Business School Press.

Kinnear TC, Taylor JR. 1991. Marketing Research; an Applied Approach. fourth edition. New York: Mc. Grow Hill.

Mulyadi. 2001. Balanced Scorecard: Alat Manajemen Kontemporer untuk Pelipatgandaan Kinerja Keuangan Perusahaan. Ed ke-1. Jakarta: Salemba Empat.

Pineno, Charles J. 2007. The business school strategy: continuous improvement by implementing the balanced scorecard. Research in Higher Education Journal 1: 68-77.

Pribadi IGO. 1995. Strategy PT Dharmala land (real estate) in competition of developers in west surabaya [tesis] . Jakarta: PPM

Scholey C, Armitage HM. 2003. Clear trails: strategy mapping may be the key to improving organizational performance. Journal CMA Management 2: 1-11.

Suhendra M. 2004. Evaluasi atas penerapan balanced scorecard sebagai sistem pengukuran kinerja perusahaan: studi kasus PT X. kajian ekonomi dan keuangan. Jurnal Riset Manajemen dan Akuntansi 8(2): 82-115.

Wibowo S, Muslim E. 2010. Perancangan balanced Scorecard sebagai alat pengukur kinerja perusahaan (Studi Kasus: PT. MCA). Jurnal Manajemen dan Akuntansi.

Wu HY. 2012. Constructing a strategy map for banking institutions with key performance indicators of the balanced Scorecard. Journal of Evaluation and Program Planning 35 (2012) 303-3 